\title{
Video Article \\ A Method to Study the C924T Polymorphism of the Thromboxane A2 Receptor Gene
}

\author{
Vincenzo De luliis ${ }^{1}$, Sebastiano Ursi ${ }^{1}$, Alfonso Pennelli ${ }^{2}$, Marika Caruso ${ }^{2}$, Sabrina Capodifoglio ${ }^{2}$, Antonio Marino ${ }^{1}$, Vincenzo Flati $^{3}$, \\ Gianfranco Vitullo ${ }^{1}$, Elena Toniato ${ }^{2}$, Iole Robuffo ${ }^{4}$, Stefano Martinotti ${ }^{1,2}$ \\ ${ }^{1}$ SS Annunziata University Hospital, Unit of Clinical Molecular Biology and Predictive Medicine, University of Chieti \\ ${ }^{2}$ Department of Medical, Oral and Biotechnological Sciences, University of Chieti \\ ${ }^{3}$ Department of Biotechnological and Applied Clinical Sciences, University of L'Aquila \\ ${ }^{4} \mathrm{CNR}$ - Institute of Molecular Genetics, Section of Chieti
}

Correspondence to: Elena Toniato at e.toniato@unich.it

URL: https://www.jove.com/video/57289

DOI: doi:10.3791/57289

Keywords: Genetics, Issue 146, Molecular Biology, Gene Expression, Restriction Enzyme Analysis, Single Nucleotide Polymorphism, Genotyping, Platelet Aggregation, Atherothrombosis

Date Published: 4/1/2019

Citation: De luliis, V., Ursi, S., Pennelli, A., Caruso, M., Capodifoglio, S., Marino, A., Flati, V., Vitullo, G., Toniato, E., Robuffo, I., Martinotti, S. A Method to Study the C924T Polymorphism of the Thromboxane A2 Receptor Gene. J. Vis. Exp. (146), e57289, doi:10.3791/57289 (2019).

\section{Abstract}

The thromboxane A2 receptor (TBXA2R) gene is a member of the G-protein coupled superfamily with seven-transmembrane regions. It is involved in atherogenesis progression, ischemia, and myocardial infarction. Here we present a methodology of patient genotyping to investigate the post-transcriptional role of the C924T polymorphism ( $r$ 4523) situated at the 3 ' region of the TBXA2 receptor gene. This method relies on DNA extraction from whole blood, polymerase chain reaction (PCR) amplification of the TBXA2 gene portion containing the C924T mutation, and identification of wild type and/or mutant genotypes using a restriction digest analysis, specifically a restriction fragment length polymorphism (RFLP) on agarose gel. In addition, the results were confirmed by sequencing the TBXA2R gene. This method features several potential advantages, such as high efficiency and the rapid identification of the C924T polymorphism by PCR and restriction enzyme analysis. This approach allows a predictive study for plaque formation and atherosclerosis progression by analyzing patient genotypes for the TBXA2R C924T polymorphism. Application of this method has the potential to identify subjects who are more susceptible to atherothrombotic processes, in particular subjects in a high-risk, aspirin-treated group.

\section{Video Link}

The video component of this article can be found at https://www.jove.com/video/57289/

\section{Introduction}

TBXA2R is a member of the G-protein coupled superfamily with seven-transmembrane regions, which are widely expressed and localized either on the cell membranes or on intracellular structures ${ }^{1,2}$. The TBXA2R signaling pathway is involved in advanced atherosclerotic processes ${ }^{3}$. Increased expression of the TBXA2 receptor was demonstrated during the atherogenesis progression, and clinical and experimental studies showed its relevant role in ischemia and myocardial infarction ${ }^{4}$. C924T, a single nucleotide polymorphism (SNP) of the TBXA2R gene, was recognized as a functional polymorphism in healthy volunteers and has been linked to clinical disorders ${ }^{5}$. Furthermore, our previous study ${ }^{6}$ demonstrated that the C924T polymorphism of the TBXA2R gene is involved in transcript stability; specifically, there is an increased instability of the mutant (TT) type transcript with respect to the wild type (CC). In addition, several stimuli such as adenosine diphosphate (ADP), epinephrine, and collagen at different concentrations induced a platelet aggregation less effective for the mutant type (TT). This is consistent with a reduced thrombus formation and hemostasis. Thus, the instability of the TBXA2R transcript and the associated reduction of platelet aggregation might be associated with a protective role for the TBXA2R TT genotype against atherothrombosis and its complications in high-risk aspirin-treated patients ${ }^{6}$.

Here, we describe a methodology for patient genotyping to investigate the post-transcriptional role of C924T polymorphism (rs4523) situated at the 3' region of the TBXA2 receptor gene. This method relies on the following steps: (1) DNA extraction from whole blood, (2) PCR amplification of the TBXA2R gene portion containing the C924T mutation, and (3) identification of wild type and/or mutant genotypes using restriction fragment length polymorphism (RFLP) on agarose gel. RFLP is a technique that exploits variations in homologous DNA sequences ${ }^{7}$. This application was used to detect DNA polymorphisms, especially SNPs, and to find and associate biological relevance in genetic variations ${ }^{8}$. The polymorphism analyzed for the first time using the RFLP-PCR in humans was the ABO blood ${ }^{9}$. The RFLP-PCR method allows the analysis of genetic mutations in homologous DNA sequences by evaluating the presence of fragments of different lengths after the DNA digestion using highly specific restriction endonucleases ${ }^{10}$

In past years, the following methodologies have been utilized for SNP analysis using the PCR technique: hybridization of short allele-specific oligonucleotides $^{11}$, allele-specific PCR ${ }^{12}$, primer extension on DNA microarrays ${ }^{13}$, oligonucleotide ligation assay ${ }^{14}$, Direct DNA sequencing for 
identifying position-specific single-nucleotide polymorphisms ${ }^{15}$, Taqman method ${ }^{16}$, extraction Matrix-Assisted Laser Desorption/lonization TimeOf-Flight (MALDI-TOF) mass spectrometry ${ }^{17}$, and GeneChips ${ }^{18}$. These techniques are not simple to use and may require expensive equipment. Conversely, the PCR-RFLP method is inexpensive, simple to use, convenient, has a high efficiency, and allows rapid identification of the C924T polymorphism. In addition, we confirmed the results by sequencing the TBXA2R gene using the Sanger method ${ }^{15}$.

This approach allows a predictive study of plaque formation and atherosclerosis progression by analyzing patient genotypes for the TBXA2R C924T polymorphism. This method could identify subjects more susceptible to atherothrombotic processes, in particular those among high-risk, aspirin-treated patients.

\section{Protocol}

The protocol follows the guidelines of the Medical Research Ethics Committee of the University of Chieti.

\section{Reagent Setup}

1. Prepare the Tris-EDTA (TE) buffer ( $\mathrm{pH}$ 8.0). Add $200 \mu \mathrm{L}$ of EDTA $0.5 \mathrm{M}$ and $1 \mathrm{~mL}$ of Tris- $\mathrm{Cl} 1 \mathrm{M}$ in a beaker and bring to $100 \mathrm{~mL}$ with sterile water. TE buffer final concentration: $10 \mathrm{mM}$ Tris-Cl, $1 \mathrm{mM}$ EDTA. Store at room temperature (RT).

2. Prepare $1 \mathrm{~L}$ of the $10 \mathrm{x}$ stock solution electrophoresis buffer (TBE). Dissolve $108 \mathrm{~g}$ of Tris Base, $55 \mathrm{~g}$ of boric acid, and $40 \mathrm{~mL}$ of EDTA $0.5 \mathrm{M}$ $(\mathrm{pH} 8)$ into a beaker, and bring to volume of $1 \mathrm{~L}$ with sterile water. Store at RT.

3. Prepare the gel loading dye. Dissolve $0.25 \mathrm{~g}$ of bromophenol blue, $0.25 \mathrm{~g}$ of xylene cyanol FF, $50 \mathrm{~g}$ of glycerol, $1 \mathrm{mM}$ of EDTA (pH 8 ) in 60 $\mathrm{mL}$ deionized or distilled water, and bring to a volume of $100 \mathrm{~mL}$ with sterile water. Store at $4{ }^{\circ} \mathrm{C}$ (for a few months) or at $-20{ }^{\circ} \mathrm{C}$ (for years)

4. Prepare $\mathbf{2 0 0} \mathrm{mL}$ of $\mathbf{2} \%$ agarose gel. Use it fresh or, alternatively, store solidified at RT for up to several weeks.

1. Dissolve $4 \mathrm{~g}$ of agarose in $200 \mathrm{~mL}$ of $1 \mathrm{x}$ TBE buffer in a $600 \mathrm{~mL}$ beaker. Stir using a magnetic mixer for about $5 \mathrm{~min}$ until the agarose is completely suspended.

2. Heat the $2 \%$ agarose solution in boiling-water or on a hot plate (for about $10 \mathrm{~min}$, until the agarose is completely dissolved). Note that the beaker with the agarose gel must be covered with aluminum foil. Alternatively, heat the uncovered beaker in a microwave at a high temperature for about 3-5 min.

3. Swirl the $2 \%$ agarose solution using a magnetic mixer, checking that the agarose is completely dissolved. NOTE: Particles of agarose appear as translucent grains prior to complete dissolution. It may be necessary to reheat particles for several minutes (about 5-10 min).

4. If a stored portion of the agarose gel is used, heat the beaker, covered with aluminum foil, in a hot-water bath (at about $60{ }^{\circ} \mathrm{C}$ ) until the agarose is dissolved. Remove with a Pasteur pipette any "trace" of solidified agarose from the surface prior to pouring.

\section{DNA Purification}

1. Perform the following before starting the purification:

1. Use human fresh whole blood samples, or thaw whole blood frozen samples quickly (for about $2-3 \mathrm{~min}$ ) in a water bath (at $37^{\circ} \mathrm{C}$ ) applying a mild agitation and then equilibrate to RT before use.

2. Mix fresh or thawed blood samples inverting the tubes several times.

2. Start the purification procedure by following the supplier's protocols for $100 \mu \mathrm{L}$ of elution volume.

3. Quantify and calculate the purity of DNA measuring the absorbance at 260,280 , and $320 \mathrm{~nm}$.

1. Use sterile water to dilute the samples and to calibrate the spectrophotometer.

2. Apply the following formula, in order to calculate the concentration of DNA sample $=50 \mu \mathrm{g} / \mathrm{mL} \times\left(A_{260}-A_{320}\right) \times$ dilution factor, and the purity of DNA $=\left(A_{260}-A_{320}\right) /\left(A_{280}-A_{320}\right)$, with an acceptable ratio between 1.7 and 1.9.

\section{PCR Amplification of DNA Samples}

1. Prepare $25 \mu \mathrm{L}$ of reaction mixture in a $0.2 \mathrm{~mL}$ micro-amplification tube, as shown in Table 1 .

2. Carry out a PCR-amplification of the purified DNA samples using an automated thermal cycler, following the amplification program shown in Table 2.

3. At the end of the PCR amplification, stop the PCR reactions by leaving the DNA samples at $4{ }^{\circ} \mathrm{C}$.

\section{RFLP of PCR Products}

1. Prepare $22.5 \mu \mathrm{L}$ of master-mix solution for each sample, so that the selected restriction enzyme digests the PCR products, as shown in Table 3.

2. Transfer $2.5 \mu \mathrm{L}$ of PCR product to a new PCR tube for each sample, using a pipette and filter tips.

3. Add $22.5 \mu \mathrm{L}$ of digestion master-mix solution to the tubes containing the PCR product of each sample, using a pipette and filter tips.

4. Incubate the reaction mixture (master-mix solution and PCR product) at $37^{\circ} \mathrm{C}$ for $4 \mathrm{~h}$.

\section{Gel Electrophoresis Analysis of PCR-RFLP Samples}

1. Stain the agarose gel by adding ethidium bromide $(\mathrm{EtBr})$ at $0.5 \mu \mathrm{g} / \mathrm{mL}$ to the gel for $10 \mathrm{~min}$. EtBr binds to the DNA, which can be visualized under ultraviolet (UV) light. 
Caution: It is important to use gloves and other protective devices during handling, storage, and disposal of EtBr, because it is a mutagen with potential carcinogenicity.

2. Pour the prepared agarose gel into a gel tray with the well comb in place, and wait until it is solidified.

3. Place the solidified agarose gel into the gel box (electrophoresis unit).

4. Fill the gel box with $1 \times$ TBE until the gel is covered.

5. With a pipette and filter tips, load $6 \mu \mathrm{L}$ of the amplified digest DNA (specifically, load $5 \mu \mathrm{L}$ of each sample and $1 \mu \mathrm{L}$ of gel loading dye) into the wells of the agarose gel. Add a DNA size marker in a separate well and in parallel with the samples.

6. Run the gel for $20-30 \mathrm{~min}$ at $100 \mathrm{~V}$.

7. With a UV-transilluminator, visualize the cleaved DNA fragments or the undigested PCR products, comparing fragments with the DNA size marker, and register the results by photography following the manufacturer's instructions.

Caution: Use protective devices (safety glasses or a face mask) around UV light sources.

\section{Representative Results}

The goal of this method is to evaluate the Thromboxane A2 receptor genotype with regard to the C924T polymorphism. The human TBXA2R gene is located on 19p13.3, spans $15 \mathrm{kbp}$, and consists of three exons separated by two introns. The C924T polymorphisms of the TBXA2R gene (of $539 \mathrm{bp}$ ) was amplified using the PCR primers shown in Figure 1, which were well-engineered to amplify a specific DNA region but not an orthologous or paralogous nonspecific region. In addition, an RFLP analysis using an Rsal restriction enzyme (Figure 1) on the PCR products was performed and the results were visualized on an agarose gel, in order to characterize the specific studied SNP.

Based on the presence of different fragment lengths after digestion of the DNA, it is possible to discriminate a patient's genotype for the C924T polymorphism. In fact, as shown on Figure 2, the homozygosity of the major allele (CC) displays two bands (395 and 144 bp), because the restriction enzyme precisely cuts the TBXA2R gene portion at the C924T polymorphism site. The homozygosity of the minor allele (TT) is demonstrated by a single band (539 bp), because the restriction enzyme cutting does not occur. The heterozygous (CT) allele shows three bands $(539,395$, and $144 \mathrm{bp}$ ). As shown in Figure 2, the C924T polymorphism, defined by Rsal digestion on PCR product, has been confirmed by sequence analysis.

\begin{tabular}{|c|c|c|}
\hline Component & Volume $(\mu \mathrm{L})$ & Final concentration \\
\hline 10x PCR buffer Tween-20 (15 M MgCl 2$)$ & 0.25 & $1.5 \mathrm{MgCl}_{2} \mathrm{mmol} / \mathrm{L}$ \\
\hline dNTP mix (10 mM) & 1 & $200 \mu \mathrm{M}$ \\
\hline Primer (forward)(10 pmol/ $/ \mu \mathrm{M})$ & 1 & $0.4 \mu \mathrm{M} / \mu \mathrm{L}$ \\
\hline Primer (reverse)(10 pmol/ $\mu \mathrm{M})$ & 1 & $0.4 \mu \mathrm{M} / \mu \mathrm{L}$ \\
\hline Taq polymerase $(5 \mathrm{U} / \mu \mathrm{L})$ & 0.2 & $1 \mathrm{U} / \mu \mathrm{L}$ \\
\hline Sample DNA (42 ng/ $\mu \mathrm{L})$ & 1 & $42 \mathrm{ng} / \mu \mathrm{L}$ \\
\hline DNase-free-water & 20.55 & \\
\hline Total & 25 & \\
\hline
\end{tabular}

Table 1: PCR amplification setup. A $25 \mu \mathrm{L}$ master-mix reaction mixture set up in a $0.2 \mathrm{~mL}$ PCR tube to amplify a single DNA sample.

\begin{tabular}{|l|l|l|l|}
\hline Standard PCR & $5 \mathrm{~min}$ & & $95^{\circ} \mathrm{C}$ \\
\hline Initial activating step & & & \\
\hline 3-step cycling & $30 \mathrm{~s}$ & & $94^{\circ} \mathrm{C}$ \\
\hline Denaturation & $60 \mathrm{~s}$ & & $55^{\circ} \mathrm{C}$ \\
\hline Annealing & $60 \mathrm{~s}$ & $30 \mathrm{cycles}$ & $72^{\circ} \mathrm{C}$ \\
\hline Extension & & & \\
\hline Number of cycles & $8 \mathrm{~min}$ & $72^{\circ} \mathrm{C}$ \\
\hline Final extension & & & \\
\hline
\end{tabular}

Table 2: PCR amplification program. Set up an automated thermal cycler in order to perform PCR and amplify the template DNA. PCR reactions are stopped by chilling at $4{ }^{\circ} \mathrm{C}$.

\begin{tabular}{|l|l|l|}
\hline Component & Volume $(\boldsymbol{\mu L})(\mathbf{n}=\mathbf{1})$ & ${\text { Volume }(\boldsymbol{\mu L})(\mathbf{n}=\mathbf{1 0})^{*}}$ \\
\hline $10 x$ enzyme buffer & 2.5 & 27.5 \\
\hline Restriction enzyme $(5 \mathrm{U} / \mu \mathrm{L})$ & 0.5 & 5.5 \\
\hline DNase-free-water & 19.5 & 214.5 \\
\hline Total & 22.5 & 247.5 \\
\hline
\end{tabular}

Table 3: Restriction enzyme digestion of PCR products. A master-mix solution is prepared so that the selected restriction enzyme digests the PCR products. *: To set up a master-mix solution for 10 samples, add $10 \%$ more, finally making up 11 samples. 


\begin{tabular}{ll}
\hline Component & \\
\hline Primer (forward) & 5' - CTTTGCAGGTCTTCATCGC - 3' \\
Primer (reverse) & 5' - CCTCTTCCAATGTCTGCATG - 3' \\
Restriction enzyme Rsal & 5' - GTVAC - 3'; 3' - CAVTG - 5'
\end{tabular}

\begin{abstract}
CTTTGCAGGTCTTCATCGCCCAGACAGTGCTGCGAAACCCGCCTGC CATGAGCCCCGCCGGGCAGCTGTCCCGCACCACGGAGAAGGAGC TGCTCATCTACTTGCGCGTGGCCACCTGGAACCAGATCCTGGACCC CTGGGTGTAC(/T)ATCCTGTTCCGCCGCGCCGTGCTCCGGCGTCTC CAGCCTCGCCTCAGCACCCGGCCCAGGTCGCTGTCCCTCCAGCCC CAGCTCACGCAGCGCTCCGGGCTGCAGTAGGAAGTGGACAGAGCG CCCCTCCCGCGCCTTTCCGCGGAGCCCTTGGCCCCTCGGACAGCC CATCTGCCTGTTCTGAGGATTCAGGGGCTGGGGGTGCTGGATGGA CAGTGGGCATCAGCAGCAGGGTTTTGGGTTGACCCCAATCCAACCC GGGGACCCCCAACTCCTCCCTGATCCTTTTACCAAGCACTCTCCCT TCCTCGGCCCCTTTTTTCCCATCCAGAGCTCCCACCCCTTCTCTGCG TCCCTCCCAACCCCAGGAAGGGCATGCAGACATTGGAAGAGG
\end{abstract}

Product size: $539 \mathrm{bp}$

Figure 1: PCR primers and Rsal restriction enzyme. The forward and reverse primers designed for amplifying the TBXA2R gene portion of $539 \mathrm{bp}$ containing the C924T polymorphism. Rsal is the restriction enzyme selected to recognize the GTAC sites. v: cutting site of Rsal enzyme. $\mathrm{C}(/ \mathrm{T})$ : C924T polymorphism. Please click here to view a larger version of this figure.

A.
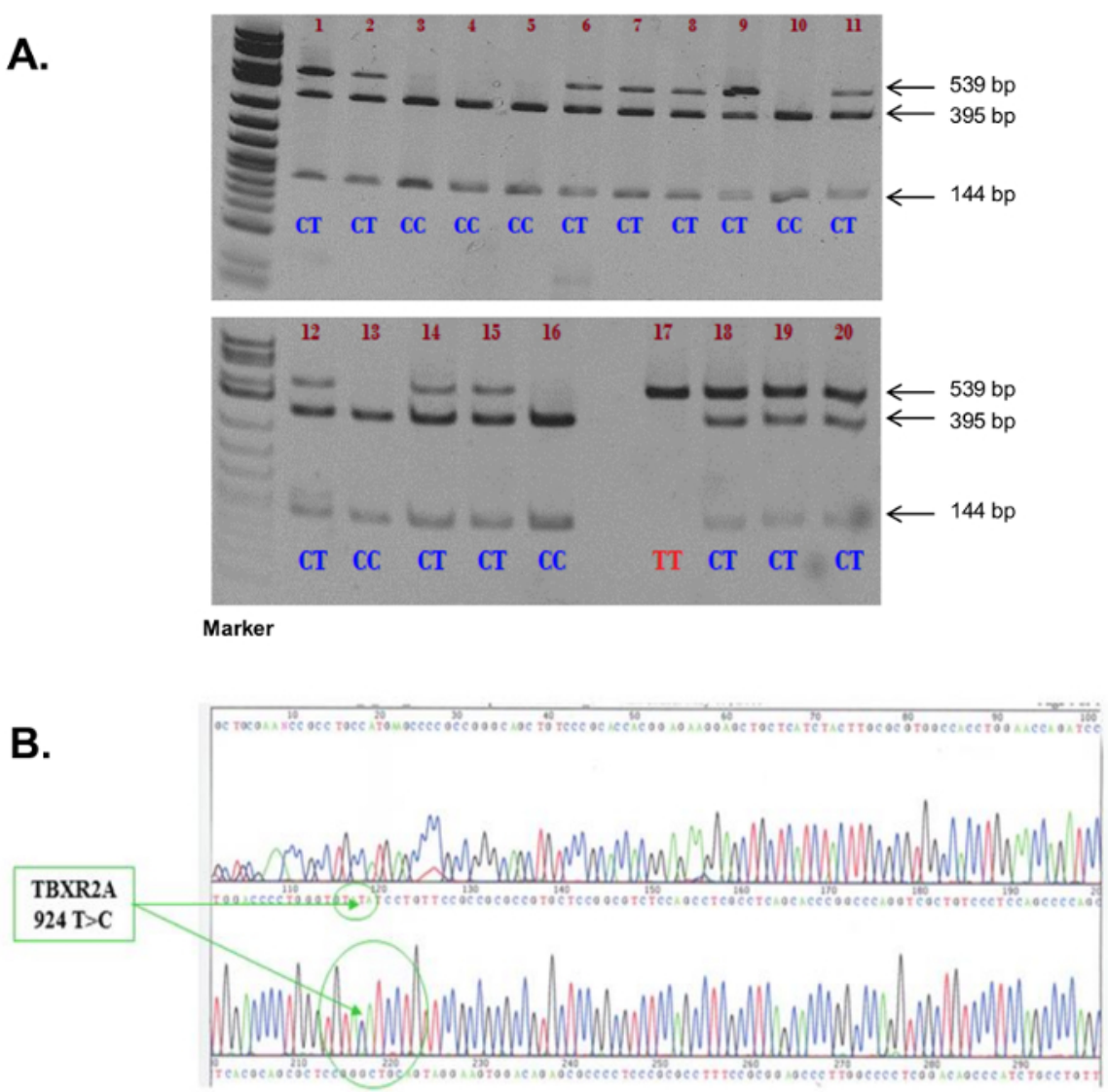

Figure 2: Electrophoretic pattern and DNA sequence analysis. (A) The C924T genotype is recognized by the RFLP pattern after digestion with the specific Rsal enzyme. (B) DNA sequence analysis: The results obtained by RFLP after digestion with the Rsal restriction enzyme were confirmed using sequence analysis showing the C924T polymorphism. This figure has been modified from De luliis et al., Prostaglandins \& Other Lipid Mediators ${ }^{6}$. Please click here to view a larger version of this figure.

\title{
Discussion
}

In the present study, we have described a methodology that allows patient genotyping in order to investigate the post-transcriptional role of C924T polymorphism (rs4523) situated at the 3' region of the TBXA2R gene. First, this method relies on DNA extraction from whole blood. In 
particular, this first process consists of a purification of total human DNA, genomic and mitochondrial, from whole blood samples fresh or frozen, treated with EDTA (either citrate or heparin). For short term storage of whole blood samples, store at $2-8^{\circ} \mathrm{C}$ for up to 10 days. For storage over 10 days, store samples at $-70^{\circ} \mathrm{C}$. The automated purification process comprises 4 steps: lyse, bind, wash, and elute. Second, the method relies on PCR amplification of the TBXA2R gene portion containing the C924T mutation. Finally, identification of the wild type and/or mutant genotype using a restriction enzyme analysis (RFLP) on agarose gel is performed.

Critical steps in the protocol are the following: (i) In the case that a portion of the agarose gel stored at RT is used, the solidified agarose can be re-dissolved over a boiling-water bath (at $60^{\circ} \mathrm{C}$ for about $15-20 \mathrm{~min}$ ) or in a microwave oven (3-5 min) prior to pouring. Note: loosen the cap when re-melting agarose in a bottle. (ii), furthermore, when re-heating agarose, evaporation will cause an increase of its concentration. For this reason, it could be useful to compensate by adding a small volume of water. (iii) DNA fragments of less than 1,000 bp were differentiated by agarose gel, and TBE buffer is recommended to obtain the best possible separation. (iv) We prefer to use an agarose gel rather than a polyacrylamide gel because the preparation of the latter is more difficult, and it takes much longer to set up. (v) The choice of the running time of the gel electrophoresis relies on the expected size of the amplification products. Based on this protocol, it is sufficient to perform an electrophoresis for $20-30 \mathrm{~min}$ at $100 \mathrm{~V}$ in $2 \%$ agarose gel, since the size of the PCR fragments ranges from $100-500 \mathrm{bp}$. (vi) It is mandatory to obtain 10 to $50 \mathrm{ng}$ of a good quality template DNA extracted from human samples. For this reason, we prefer to use an automated DNA purification rather than a semi-automated or manual one. (vii) Prepare the master-mix reaction for PCR amplification and the master-mix solution for PCR products digestion, adding $10 \%$ more (to account for loss of liquid during pipetting) to the volume calculated multiplied by the number of samples for the volume required for one DNA sample.

The most frequent pitfall of the method is the presence of extra amplification products due to an incorrect thermal cycler program, an incorrect amplification master-mix preparation, or a DNA template contamination. Furthermore, the absence of PCR products may be due to inactivated Taq polymerase or an incorrect thermal cycler run. In addition, the presence of unexpected fragments may be due to PCR product contamination or to an incomplete digestion from either an inactivated enzyme, too little amount of restriction enzyme volume, or a too short incubation time.

In the past years, the following methodologies have been utilized for SNP analysis using the PCR technique: hybridization of short allele-specific oligonucleotides $^{11}$, allele-specific PCR ${ }^{12}$, primer extension on DNA microarrays ${ }^{13}$, oligonucleotide ligation assay ${ }^{14}$, Direct DNA sequencing for identifying position-specific single-nucleotide polymorphisms ${ }^{15}$, Taqman method ${ }^{16}$, extraction Matrix-Assisted Laser Desorption/lonization Time-Of-Flight (MALDI-TOF) mass spectrometry ${ }^{17}$, and GeneChips ${ }^{18}$. These methods are not ideal because they are not simple to use and/or require expensive equipment. Conversely, the PCR-RFLP method described in this study is inexpensive, simple to use, convenient, has a high efficiency, and allows rapid identification of the C924T polymorphism. A limitation to the present method is that it can only be used for a small number of SNPs and for a few samples in a working session.

For future applications, this method can be used for predictive studies concerning plaque formation and atherosclerosis progression by analyzing the patient genotypes for the TBXA2R C924T polymorphism. Furthermore, this method could identify subjects more susceptible to atherothrombotic processes, in particular, high-risk patients treated with aspirin. Finally, this method could be applied to study other polymorphisms involved in personalized medicine for specific drugs (for example, anticoagulants and anticonvulsants) in order to understand the appropriate drug dosage and the individual pharmacological and clinical response for each patient before beginning therapy and to avoid adverse effects.

\section{Disclosures}

The authors have nothing to disclose.

Acknowledgments

This project was partially funded by $60 \%$ Ateneo grants from Ministero dell'Università, Italy to S.M., and E.T. We also received partial contributions to research expenses by the Department of Medical, Oral and Biotechnological Sciences, University of Chieti "G. d'Annunzio".

1. Shen, R.F., Tai, H.H. Thromboxanes: synthase and receptors. J Biomed Sci. 5 (3), 153-172 (1998).

2. Nusing, R.M., Hirata, M., Kakizuka, A., Eki, T., Ozawa, K., Narumiya, S. Characterization and chromosomal mapping of the human thromboxane A2 receptor gene. J Biol Chem. 268 (33), 25253-25259 (1993).

3. Cyrus, T., Ding, T., Praticò, D. Expression of thromboxane synthase, prostacyclin synthase and thromboxane receptor in atherosclerotic lesions: correlation with plaque composition. Atherosclerosis. 208 (2), 376-381 (2010).

4. Cipollone, F., et al. A Polymorphism in the Cyclooxygenase 2 Gene as an Inherited Protective Factor Against Myocardial Infarction and Stroke. JAMA. 291 (18), 2221-8 (2004).

5. Fontana, P., et al. Identification of functional polymorphisms of the thromboxane A2 receptor gene in healthy volunteers. Thromb Haemost. 96 (3), 356-60 (2006).

6. De luliis, V., et al. Differential TBXA2 receptor transcript stability is dependent on the C924T polymorphism. Prostaglandins Other Lipid Mediat. pii: S1098-8823(17)30006-0 (2017).

7. Saiki, R.K. et al. Enzymatic amplification of beta-globin genomic sequences and restriction site analysis for diagnosis of sickle cell anemia. Science. 230 (4732), 1350-1354 (1985).

8. Collins, F.S., Brooks, L.D., Chakravarti, A. A DNA polymorphism discovery resource for research on human genetic variation. Genome Res. 8 (12), 1229-1231 (1998).

9. Lee, J.C.-I., Chang, J.-G. ABO genotyping by polymerase chain reaction. J. Forensic Sci. 37 (5), 1269-1275 (1992).

10. Masao, O., Hirofumi, F., Jerzy, K.K., Hidetoshi, I. Single nucleotide polymorphism detection by polymerase chain reaction-restriction fragment length polymorphism. Nature Protocols. 2 (11), 2857-2864 (2007). 
11. Iwasaki, H. et al. Accuracy of genotyping for single nucleotide polymorphisms by a microarray-based single nucleotide polymorphism typing method involving hybridization of short allele-specific oligonucleotides. DNA Res. 9 (2), 59-62 (2002).

12. Papp, A.C., Pinsonneault, J.K., Cooke, G., Sadee, W. Single nucleotide polymorphism genotyping using allele-specific PCR and fluorescence melting curves. Biotechniques. 34 (5), 1068-1072 (2003).

13. O'Meara, D., Ahmadian, A., Odeberg, J., Lundeberg, J. SNP typing by apyrase-mediated allele-specific primer extension on DNA microarrays. Nucleic Acids Res. 30 (15), e75 (2002).

14. Pickering, J. Integration of DNA ligation and rolling circle amplification for the homogeneous, end-point detection of single nucleotide polymorphisms. Nucleic Acids Res. 30 (12), e60 (2002).

15. Chatterjee, P.D. Direct sequencing of bacterial and $P 1$ artificial chromosome-nested deletions for identifying position-specific singlenucleotide polymorphisms. Proc. Natl. Acad. Sci. USA. 96 (23), 13276-13281 (1999).

16. Livak, K.J. Allelic discrimination using fluorogenic probes and the 5' nuclease assay. Genet. Anal. 14 (5-6), 143-149 (1999).

17. Haff, L.A., Smirnov, I.P. Single-nucleotide polymorphism identification assays using a thermostable DNA polymerase and delayed extraction MALDI-TOF mass spectrometry. Genome Res. 7 (4), 378-388 (1997).

18. Gunderson, K.L., Steemers, F.L., Lee, G., Mendoza, L.G., Chee, M. A genome-wide scalable SNP genotyping assay using microarray technology. Nat. Genet. 37 (5), 549-554 (2005). 